\title{
O CURRÍCULO PARA O ENSINO MÉDIO EM SUAS DIFERENTES MODALIDADES: CONCEPÇÕES, PROPOSTAS E PROBLEMAS
}

\author{
MARISE NOGUEIRA RAMOS*
}

\begin{abstract}
RESUMO: $\mathrm{O}$ artigo discute políticas curriculares para o ensino médio no Brasil, problematizando a reforma curricular de FHC, passando às ações do governo Lula, bem como ao movimento de defesa do ensino médio integrado. Aborda as políticas atuais, considerando perspectivas virtuosas trazidas pelas novas Diretrizes Curriculares Nacionais. Considera que o programa de incentivo a propostas curriculares "inovadoras" no ensino médio transita entre o avanço conceitual da relação entre trabalho, ciência e cultura, e a reificação de atividades e métodos ativos. Conclui que as dificuldades enfrentadas na luta de uma proposta contra-hegemônica não são somente de ordem conceitual, mas uma expressão da capacidade da classe dirigente em manter seus princípios vigorando no senso comum da sociedade.
\end{abstract}

Palavras-chave: Ensino médio. Ensino médio integrado. Currículo do ensino médio. Currículo integrado.

\section{HIGH SCHOOL CURRICULUM IN ITS DIFFERENT MODALITIES: CONCEPTIONS, PROPOSALS AND PROBLEMS}

\begin{abstract}
This paper discusses the curriculum policies for Brazilian high school, from the curricular reform of the FHC government, to the actions of the Lula government and the movement to defend integrated high school. It approaches the current policies considering the virtuous perspectives brought forth by the new National Curricular Guidelines. It assumes that programs to induce "innovative" curriculum proposals oscillate between the conceptual advance of the relation between work, science and culture, and the reification of activities and active methods It concludes that the difficulties faced by a counter-hegemonic proposal are not only due to its concepts, but also to the capacity of the ruling class to maintain its principles in force in the society's common sense.
\end{abstract}

Key words: High school. Integrated high school. Curriculum of high school. Integrated curriculum.

\footnotetext{
* Doutora em Educação e professora adjunta do Programa de Pós-Graduação em Políticas Públicas e Formação Humana e da Faculdade de Educação da Universidade do Estado do Rio de Janeiro (UERJ). E-mail:ramosmn@gmail.com
} 


\section{LE PROGRAMME SCOLAIRE DU LYCÉE DANS SES DIFFÉRENTES MODALITÉS: CONCEPTIONS, PROPOSITIONS ET PROBLÈMES}

RÉSUMÉ: Cet article discute les politiques de programmes scolaires des lycées brésilien depuis la réforme du gouvernement FHC jusqu'aux actions du gouvernement Lula et au mouvement de défense de programmes scolaires intégrant l'enseignement technique. Il aborde les politiques actuelles en considérant les perspectives vertueuses des nouvelles Directives nationales des programmes scolaires. Il considère que les propositions de programmes "novatrices" oscillent entre les progrès conceptuels de la relation travail, science et culture, et la réification des activités e des méthodes actives. Il conclut que les difficultés affrontées par une proposition contre hégémonique se doivent autant à leurs concepts, qu'à la capacité de la classe dirigeante à maintenir ses principes en vigueur dans le sens commun de la société.

Mots-clés: Lycée. Lycée et enseignement technique intégrés. Programme scolaire du lycée. Programme scolaire intégrant l'enseignement technique.

\section{Introdução}

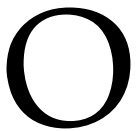

sentido do trabalho no ensino médio certamente é uma das questões que clivaram, historicamente, a natureza do currículo nessa etapa de formação. Isto porque é nessa fase que ocorre a explicitação do modo como o conhecimento se relaciona com o trabalho. Também nesse momento, tanto os jovens estão projetando suas vidas como componentes da população economicamente ativa, o que inclui as escolhas profissionais, quanto os adultos veem nessa etapa de ensino a possibilidade de se qualificarem como trabalhadores.

A delimitação de nossa análise inicialmente nos anos de 1990 se justifica pelo fato de as reformas curriculares empreendidas a partir da aprovação da Lei n. 9.394/96 terem se baseado numa suposta definição da finalidade do ensino médio: formar para a vida. Tal definição foi apoiada em uma dicotomia instaurada pelo Decreto n. 2.208/97, ao determinar que a educação profissional de nível técnico teria organização curricular própria e independente do ensino médio, podendo ser oferecida de forma concomitante ou sequencial a este. Assim se realizou uma verdadeira reforma curricular, tendo como doutrina o exposto nas respectivas Diretrizes Curriculares Nacionais. ${ }^{1}$

Passados sete anos de defesa de uma concepção de ensino médio integrado, encontramo-nos hoje com perspectivas virtuosas trazidas pela aprovação das novas Diretrizes Curriculares Nacionais do Ensino Médio. Ao mesmo tempo, as possibilidades de incentivo a propostas curriculares "inovadoras" transitam entre o avanço conceitual da relação entre trabalho, ciência e cultura, e a reificação de atividades e métodos ativos para tornar o currículo interessante aos estudantes.

Se não se trata de apontar dicotomias, ao contrário, pretendemos apontar e discutir contradições e possibilidades que se abrem num momento em que um 
significativo acúmulo de estudos e debates pode influir, em certa medida, as regulamentações vigentes. Por isso a necessidade de recuperar a reforma curricular de FHC, apontar medidas do governo Lula e, depois, as proposições vinculadas à concepção de ensino médio integrado. Finalmente, discutimos perspectivas e possibilidades presentes na política contemporânea.

Nossas conclusões demonstram que as dificuldades de se implantar uma proposta contra-hegemônica não são somente de ordem conceitual, mas uma expressão da capacidade da classe dirigente em manter seus princípios vigorando no senso comum da sociedade.

Enfim, contribuir para a análise e a formulação de políticas, a partir da exposição da problemática e de perspectivas de enfrentamento, tendo o trabalho escolar como uma das dimensões fundamentais da formação intelectual e cultural dos trabalhadores, é, em certa medida, uma pretensão que nos colocamos na elaboração deste texto.

\section{A reforma curricular do ensino médio no período FHC: a introdução da pedagogia das competências na educação básica}

Uma vez determinada a separação do ensino médio da educação profissional, os fundamentos da reforma curricular do ensino médio foram elaborados na forma das respectivas Diretrizes Curriculares Nacionais. Tais fundamentos podem ser assim resumidos: a) reiteração das finalidades previstas pela Lei de Diretrizes e Bases (LDB) para o ensino médio; b) organização do currículo com base em áreas do conhecimento; c) destaque às competências de caráter geral - especialmente a capacidade de aprender - no lugar do estabelecimento de disciplinas e conteúdos específicos; d) definição de princípios axiológicos; e) definição de princípios pedagógicos; f) regulamentação da parte diversificada do currículo.

Ao ter suas finalidades sintetizadas no slogan "ensino médio agora é para a vida", o trabalho e a cidadania foram definidos como contextos do currículo. A organização em áreas de conhecimento não dispôs de um consenso. Mas as Diretrizes Curriculares Nacionais para o Ensino Médio (DCNEM) foram claras ao recomendarem a organização dos conteúdos de ensino em estudos ou áreas interdisciplinares e projetos. A redefinição curricular nesse sentido implicaria, também, "(re)significar os conteúdos curriculares como meios para constituição de competências e valores, e não como objetivos do ensino em si mesmos" (Brasil, 1998, p. 37). Como componentes curriculares, ${ }^{2}$ então, teríamos um conjunto contextualizado de situações voltadas para a geração de competências. Os métodos, por sua vez, assumiram papel relevante nessas orientações. 
A pedagogia das competências no ensino médio teve como fundamento os princípios axiológicos expostos nas diretrizes. Trata-se, na verdade, de uma releitura das quatro grandes necessidades de aprendizagem relatadas na Reunião Internacional sobre Educação para o Século xxI da unEsco: aprender a conhecer, aprender a fazer, aprender a conviver e aprender a ser.

O princípio da estética da sensibilidade converge com o aprender a conhecer e com o aprender a fazer. A política da igualdade, plano do aprender a conviver, teria como ponto de partida o reconhecimento dos direitos humanos e o exercício dos direitos e deveres de cidadania. Finalmente, a ética da identidade corresponde ao princípio do aprender a ser, pelo reconhecimento da identidade própria e reconhecimento do outro.

Quanto aos princípios pedagógicos, a interdisciplinaridade reduziu-se a recurso didático para "relacionar as disciplinas em atividades ou projetos de estudo, pesquisa e ação" (Brasil, 1998, p. 39). A contextualização seria outro recurso para ampliar as possibilidades de interação das disciplinas de uma área de conhecimento e entre as áreas.

O pensamento de Phillippe Perrenoud foi enunciado como uma das principais referências dessas proposições. Este expõe duas ideias sobre a pedagogia das competências especialmente em uma obra em que discute a construção de competências desde a escola (Perrenoud, 1999). Para ele, a mudança fundamental no currículo ocorreria em relação ao referencial a partir do qual se selecionariam os conteúdos, ou seja, não mais a partir das ciências, mas da prática ou das condutas esperadas.

Formulou-se, assim, a pedagogia das competências como uma corrente pedagógica que orientou a reforma curricular realizada ao final dos anos de 1990. A aproximação com o escolanovismo não é casual, posto ser possível encontrar seus fundamentos no pragmatismo. Também elementos do construtivismo piagetiano subjazem à concepção de competência difundida pela reforma. Mas é para a armadilha do tecnicismo e do condutivismo que essa pedagogia tendeu a levar as elaborações curriculares nesse tempo. ${ }^{3}$

Nesse período, considerando a inexistência de recursos vinculados constitucionalmente para o ensino médio, o Ministério da Educação (MEC) implementou a reforma, assistindo financeiramente os estados com recursos do contrato de empréstimo obtidos com o Banco Interamericano de Desenvolvimento (вID), o qual deu origem ao Programa de Expansão e Melhoria do Ensino Médio (PROMED). Este programa contava com componentes de apoio à expansão e melhoria da rede escolar, de formação docente e de estudos e pesquisas, visando, especialmente, à efetivação da reforma curricular. 
O MEC valeu-se do PROMED para prestar assessoria aos estados, com estratégias que variaram desde a formação docente até a publicação de materiais que operacionalizavam as DCN. Os Parâmetros Curriculares Nacionais do Ensino Médio (PCN) e os posteriores $\mathrm{PCN}^{+}$compõem esse conjunto. $\mathrm{O}$ que neles se viu, na verdade, foi o desdobramento das áreas de conhecimento em disciplinas e o enunciado de temas e sequências de atividades que poderiam guiar a proposta curricular e o processo de ensino e aprendizagem nas escolas.

Assim, grades curriculares passaram a mostrar as áreas de conhecimento e respectivas disciplinas; cargas horárias dos tempos letivos; carga horária e disciplinas e/ou atividades da parte diversificada do currículo. Também planos de curso e de aulas se preocuparam em enunciar as competências. Adotaram-se as nomenclaturas postas pelas diretrizes, assim como situações de contextualização e de interdisciplinaridade. O que a reforma não considerou, entretanto, é que os problemas que se propôs a resolver não são exclusivamente pedagógicos. Antes, possuem determinações políticas, por um lado, e epistemológicas, por outro. A não compreensão dessas determinações desencadeou inúmeras inovações, sem promover a compreensão do problema na sua essência e em sua superação.

\section{O movimento contra-hegemônico dos anos 2000: um currículo in- tegrado}

O ano de 2003 marca o início de um novo período político no país. Ascende à presidência da República um candidato que se fez pela luta sindical. Seu projeto de governo, em grandes linhas, reunia históricas reivindicações populares. No caso da educação, além de uma agenda de mudanças, a revogação do Decreto n. 2.208/1997, pedra fundamental da reforma curricular do ensino médio na década anterior, era compromisso inviolável. Após um processo de disputas e negociações que vai de 2003 a meados de 2004, o Decreto n. 5.154/2004 é exarado.

O texto da lei se limita a admitir que a articulação entre o ensino médio e a educação profissional possa ocorrer de forma integrada, o que significa a formação básica e a profissional acontecerem numa mesma instituição de ensino, num mesmo curso, com currículo e matrículas únicas. Discussões e propostas de educadores, porém, vão mais longe. Ao defenderem a proposta de Ensino Médio Integrado, resgatam fundamentos filosóficos, epistemológicos e pedagógicos da concepção de educação politécnica e omnilateral e de escola unitária baseado no programa de educação de Marx e Engels e de Gramsci. Tais fundamentos convergem para uma concepção de currículo integrado, cuja formulação incorpora contribuições já existentes sobre o mesmo tema ${ }^{4}$ mas pressupõe a possibilidade de se pensar um currículo convergente com os propósitos da formação integrada - formação do sujeito em múltiplas 
dimensões, portanto, omnilateral - e da superação da dualidade estrutural da sociedade e da educação brasileiras.

O currículo assim pensado é uma relação entre partes e totalidade. Ele organiza o conhecimento e desenvolve o processo de ensino-aprendizagem de forma que os conceitos sejam apreendidos como sistema de relações históricas e dialéticas que constituem uma totalidade concreta. Esta concepção compreende que as disciplinas escolares são responsáveis por permitir apreender os conhecimentos já construídos em sua especificidade conceitual e histórica; ou seja, como as determinações mais particulares dos fenômenos que, relacionadas entre si, permitem compreendê-los.

A interdisciplinaridade, como método, é a reconstituição da totalidade pela relação entre os conceitos originados a partir de distintos recortes da realidade; isto é, dos diversos campos da ciência representados em disciplinas. Isto tem como objetivo possibilitar a compreensão do significado dos conceitos, das razões e dos métodos pelos quais se pode conhecer o real e apropriá-lo em seu potencial para o ser humano.

Não se trata simplesmente de se contextualizar conhecimentos científicos no trabalho e na cidadania - relações designadas como contextos -; aliás, nem o trabalho é delimitado como contexto, nem este forma uma dualidade com a cidadania. Trabalho, ciência e cultura são dimensões da vida humana que devem ser integradas ao currículo e no currículo, tendo o trabalho como princípio educativo.

$\mathrm{O}$ fato de o trabalho ser mediação primeira entre o homem e a realidade - e, assim, modelo de toda a práxis social (Lukács, 1981) - explica por que o ser humano é produtor de conhecimento e de cultura. A produção humana, porém, se realiza sempre sob condições sociais e históricas determinadas pelas relações sociais. Assim, ter o trabalho como princípio educativo implica referir-se a uma formação baseada no processo histórico e ontológico de produção da existência humana.

Sob esse prisma, os processos de produção (de bens e serviços de toda ordem), como partes de uma totalidade que é a produção da existência humana, podem ser estudados em múltiplas dimensões, tais como econômica, produtiva, social, política, cultural, técnica, entre outras. Os conceitos "pontos-de-partida" para esse estudo convertem-se em conteúdos de ensino organizados nas diferentes áreas de conhecimento e disciplinas. O currículo integrado elaborado sobre essas bases não hierarquiza os conhecimentos nem os respectivos campos das ciências, mas os problematiza em suas historicidades, relações e contradições.

Por esse caminho, perceber-se-á que conhecimentos gerais e conhecimentos profissionais somente se distinguem metodologicamente e em suas finalidades situadas historicamente. Porém, epistemologicamente, esses conhecimentos formam uma unidade. No currículo que integra formação geral, técnica e política (que, portanto, não reduz trabalho e cidadania a contextos nem os separa como universos 
distintos), o estatuto de conhecimento geral de um conceito está no seu enraizamento nas ciências como "leis gerais" que explicam fenômenos. Um conceito específico, por sua vez, configura-se pela apropriação de um conceito geral com finalidades restritas a objetos, problemas ou situações de interesse produtivo. Em razão disso, no currículo integrado nenhum conhecimento é só geral, posto que estrutura objetivos de produção; nem somente específico, pois nenhum conceito apropriado produtivamente pode ser formulado ou compreendido desarticuladamente da ciência básica.

Esses preceitos organizariam a base unitária do ensino médio integrado, ${ }^{5}$ seja ele profissionalizante ou não. Somente com esta base, trabalho, ciência e cultura poderiam ser convertidos em contextos da formação específica. O ensino médio integrado à educação profissional, além de ter o trabalho como princípio educativo, o toma também como contexto econômico-produtivo, visando a preparar as pessoas para o exercício profissional nesse contexto. Os projetos de iniciação científica, de desenvolvimento cultural, por sua vez, se aportam também na delimitação da ciência e da cultura como contextos de produção e de criação; e, como tal, podem ser valorizados no currículo do ensino médio, mesmo na forma integrada à educação profissional.

Além do ensino médio integrado para alunos na idade prevista (14 a 17 anos), o governo instituiu o Programa Nacional de Integração da Educação Profissional com a Educação Básica na Modalidade de Educação de Jovens e Adultos (PROEjA). ${ }^{6}$ Assim, toda a elaboração anterior referente ao ensino médio integrado abrange também a integração da educação básica com a profissional na EJA.

Há um desafio específico nesse caso, que é o caráter instrumental que a formação profissional pode adquirir para essas pessoas, considerando a premência que têm em relação ao ingresso e permanência na atividade produtiva. Portanto, para essas pessoas, a relação entre educação e trabalho é muito mais imediata e contraditória. Para elas, o sentido do conhecimento não está em proporcionar, primeiro, a compreensão geral da vida social e, depois, instrumentalizá-las para o exercício profissional. Na maioria das vezes, o acesso ou o retorno à vida escolar ocorre motivado pelas dificuldades enfrentadas no mundo do trabalho, pela necessidade de nele se inserir e permanecer. Por essas razões, a EJA deve reconhecer o trabalho como princípio educativo, antes por sua característica ontológica e, a partir disso, na sua especificidade histórica que inclui o enfrentamento das instabilidades do mundo contemporâneo.

Os estudantes da EjA são sujeitos de conhecimento. Suas experiências educativas - formais ou não - lhes proporcionaram aprendizagens que devem se constituir como pontos de partida para novas aprendizagens quando retornam à educação formal. Isto exige repensar tempos e espaços curriculares. A delimitação de cargas horárias para a formação geral e a profissional, por exemplo, é um problema. O recorte e a pré-determinação de cargas horárias destinadas a cada dimensão da formação podem causar dualismo e superposições, comprometendo-se a integração. 
Certamente, compreender e realizar a unidade como síntese do diverso e a totalidade para além da soma das partes são meios para superar tais limitações e dicotomias e avançarmos conceitual e empiricamente na EJA.

\section{Integração ou inovação: perspectivas atuais para o currículo do en- sino médio}

Ao final do ano de 2008, o currículo do ensino médio chegou a ter lugar na imprensa, ${ }^{7}$ com declarações oficiais de que esse ensino viveria uma "crise aguda" e que "as políticas adotadas pelo governo para enfrentá-la não surtiram efeito". Constava, então, naquele momento, que o ministro da Educação "está[va] anunciando uma proposta de alteração do currículo desse ciclo de ensino para torná-lo mais técnico e voltado à realidade do mercado de trabalho".

Elaborada por um grupo de trabalho constituído por representantes do MEC e da Secretaria de Assuntos Estratégicos, uma proposta de experiência curricular inovadora do ensino médio foi apresentada ao Conselho Nacional de Educação $(\mathrm{CNE})^{8}$ e aprovada por este no mérito e na relevância, para ser realizada em regime de articulação e colaboração entre os sistemas de ensino. Nesse parecer, o cNE faz recomendações para a elaboração da proposta curricular, em que se destacam a diversidade de modelos curriculares; a flexibilidade curricular visando ao atendimento da pluralidade de interesses dos estudantes; a inclusão de componentes curriculares obrigatórios e variáveis; a diversidade de tempos e situações curriculares; as atividades de interação com as comunidades; e a interdisciplinaridade realizada nas dimensões estruturantes do currículo - trabalho, ciência, tecnologia e cultura.

Além dessas, recomendações organizativas também foram feitas, ressaltando-se a necessidade de se melhorar a infraestrutura das escolas; de se compor um grupo gestor com integrantes dos sistemas de ensino e das comunidades; de se implementarem os estágios curriculares; de se priorizar o acesso de alunos oriundos do ensino fundamental público; de se instituir uma Rede Nacional de Intercâmbio de Escolas de Ensino Médio Inovador; e, finalmente, de se adotarem estratégias progressivas para se atingir a integralidade da carga horária ampliada, com $20 \%$ de atividades optativas para os alunos e a dedicação de tempo integral dos professores.

Esta proposta foi posteriormente implementada pelo MEC na forma do Programa Ensino Médio Inovador, ${ }^{9}$ com vistas a

(...) apoiar as Secretarias Estaduais de Educação e do Distrito Federal no desenvolvimento de ações de melhoria da qualidade do ensino médio não profissionalizante, com ênfase nos projetos pedagógicos que promovam a educação científica e humanística, 
a valorização da leitura, da cultura, o aprimoramento da relação teoria e prática, da utilização de novas tecnologias e o desenvolvimento de metodologias criativas e emancipadoras. (Art. $2^{\circ}$, Portaria n. 971/2009)

O foco do programa foi o ensino médio não profissionalizante, de modo a incentivar que este fosse reestruturado, combinando formação geral, científica, tecnológica e cultural com conhecimentos técnico-experimentais. Uma preocupação constante é a manutenção dos jovens na escola, o que se espera conseguir mediante o diálogo com seus interesses e o compromisso com a aprendizagem significativa e com o desenvolvimento da autonomia intelectual dos estudantes. Por meio do Programa Ensino Médio Inovador, seria prestado apoio técnico e financeiro a ações dos sistemas estaduais de ensino, mediante a seleção de propostas e posterior celebração de convênio, execução direta ou descentralização de recursos.

Os documentos oficiais citados foram precedidos de um documento (Brasil, 2009), do qual constam, além de orientações de implementação e execução, os "pressupostos para um currículo inovador de ensino médio", os quais subsidiam o parecer do CNE. Ideias recorrentes nesses pressupostos são a articulação das disciplinas com atividades integradoras; a definição da relação entre trabalho, ciência, tecnologia e cultura como eixo do currículo; a adoção do trabalho como princípio educativo nas dimensões ontológica e histórica; e a consolidação de uma base unitária do currículo, a partir da qual se promoveria a diversidade.

Encontram-se, aqui, vários preceitos da concepção de ensino médio integrado, ainda que não apareçam orientações diretivas quanto aos componentes do currículo. É numa versão do ano de 2011 que elas podem ser encontradas, em consonância com as novas Diretrizes Curriculares Nacionais para a Educação Básica e para o Ensino Médio. ${ }^{10}$ Tais orientações, nesse novo documento, se manifestam principalmente quando da exposição sobre o Plano de Ação Pedagógico (PAP). Neste plano, dá-se ênfase à descrição de ações, metas e previsão de gastos com ações/projetos e componentes curriculares vinculados às seguintes práticas que se pretende apoiar: ações de ampliação do tempo do aluno na escola; oferta de componentes curriculares optativos; ações de incentivo à pesquisa e de iniciação científica; projetos de produção de vídeos, mídias e cinema; projetos de incentivo a arte e a cultura; projetos de produção textual, jornal e de incentivo a leitura; projetos de incentivo ao lúdico, aos esportes e ao lazer (Brasil, 2011).

Incentivos a inovações curriculares nessa direção não podem ser considerados negativos. Ao contrário, trata-se de práticas pedagógicas que dinamizam o processo de ensino-aprendizagem. Destaque-se, ainda, que há a preocupação com o fato de esses projetos e atividades estarem vinculados aos componentes curriculares obrigatórios do ensino médio. ${ }^{11}$ Não obstante, é preciso considerar que o desafio mais ardiloso de uma proposta curricular de ensino médio no sentido da formação integrada 
está na compreensão do significado do conhecimento científico, nos critérios de sua seleção e na forma de organizá-los e abordá-los.

As DCNEM aprovadas apresentam indicações sobre a relevância desse tipo de conhecimento na formação escolar e destaca, ainda, a preocupação que o currículo deve ter com a sua historicidade, reconhecendo a relação entre trabalho, ciência e cultura como o eixo integrador dos conhecimentos, por meio do qual essa dimensão pode ser abrangida. Afirmam que a integração entre as dimensões do trabalho, ciência, tecnologia e cultura, na perspectiva do trabalho como princípio educativo, tem por fim propiciar a compreensão dos fundamentos científicos e tecnológicos dos processos sociais e produtivos, devendo orientar a definição de toda proposição curricular, constituindo-se no fundamento da seleção dos conhecimentos, disciplinas, metodologias, estratégias, tempos, espaços, arranjos curriculares alternativos e formas de avaliação.

No referido parecer, as atividades integradoras - fortemente destacadas no documento sobre o Ensino Médio Inovador, como já assinalamos - devem ser concebidas a partir do trabalho como primeira mediação entre o homem e a natureza e entre suas relações com a sociedade e com cada uma das outras dimensões curriculares reiteradamente mencionadas. Assim, sugerem que tais atividades sejam desenvolvidas a partir de várias estratégias/temáticas que incluam a problemática do trabalho de forma relacional.

Com destaque para o significativo avanço conceitual, mantém-se, porém, a ideia de se relacionarem situações reais existentes nas práticas sociais concretas ou simulações com os conteúdos das disciplinas. Na integração que sustenta a concepção de ensino médio integrado não se prevê somente a relação entre situações e conteúdos de ensino, mas os próprios conhecimentos são tratados como um sistema de relações.

Posto nesse sentido, o trabalho pedagógico assume a interdisciplinaridade como necessidade e como problema, porque coloca a questão do conhecimento escolar também no plano epistemológico, especialmente por serem as disciplinas científicas um dos principais campos de referência para a seleção de conteúdos.

A interdisciplinaridade, vista sob esse prisma, se torna uma necessidade porque a parte que isolamos, ou arrancamos do contexto originário do real no trabalho científico - sessões tematizadas da realidade - para ser explicada efetivamente, isto é, revelar no plano do pensamento e do conhecimento as determinações que assim a constituem (como conceitos e teorias) como parte, tem que ser explicitada na integridade das características e qualidades da totalidade. O trabalho interdisciplinar torna-se, então, um problema na produção do conhecimento e nos processos de ensino, ao se propor a responder a esta necessidade (Frigotto, 1995). 
A interdisciplinaridade como método é a perspectiva ressaltada pelas DCNEM, quando afirmam considerar, nos mesmos termos das diretrizes curriculares nacionais da educação básica, ${ }^{12}$ que, "pela abordagem interdisciplinar ocorre a transversalidade do conhecimento constitutivo de diferentes disciplinas, por meio da ação didático-pedagógica mediada pela pedagogia dos projetos temáticos" (Brasil, 2011, p. 44). Essa compreensão, de ordem metodológica, não se opõe à anterior, de ordem epistemológica. Porém, deixado somente no primeiro plano, o trabalho pedagógico interdisciplinar pode não passar do estabelecimento formal de relações entre conteúdos de ensino de diferentes disciplinas e/ou desses com situações e simulações da realidade. Superar essa delimitação é, também, uma necessidade.

Ao assumir o trabalho como princípio educativo - mediação de primeira ordem entre o ser humano e o meio ambiente -, as estratégias pedagógicas adquirem ênfase no sentido de possibilitar a compreensão do processo social, cultural e histórico da ciência e da tecnologia mediado pelo trabalho. Se aqui há uma convergência com o que Gramsci (1991) define como o método da escola ativa e criadora, teríamos a perspectiva histórica e dialética do trabalho pedagógico. Como afirmamos em outro texto (Ramos, 2005), é histórico porque se ocupa em evidenciar, juntamente com os conceitos, as razões, os problemas, as necessidades e as dúvidas que constituem o contexto de produção de um conhecimento; dialético, porque a razão do estudo dos fundamentos científicos, sócio-históricos e culturais da produção moderna possibilitaria compreendê-los como um sistema de relações que os constituem.

Desse modo, parece-nos que as diretrizes curriculares atuais fornecem subsídios relevantes para se pensar o currículo não somente como artefato pedagógico, mas nos desafiam, pelas questões que suscitam, a colocá-lo no plano epistemológico. Nesses termos, as orientações presentes no atual documento sobre o Ensino Médio Inovador, se apropriadas com a base teórica que orienta as DCNEM e com as problematizações que ela suscita, podem trazer perspectivas fecundas para o currículo do ensino médio.

Haveria ainda, entretanto, que se problematizar a ênfase que ambos os documentos conferem aos interesses e aspirações dos estudantes. Saviani (1985) demonstrou os deslocamentos que ocorreram da pedagogia tradicional para a pedagogia nova: do intelecto para o sentimento; do lógico (a dimensão objetiva do conhecimento) para o psicológico (a dimensão subjetiva do conhecimento); dos conteúdos para os métodos; do professor para o aluno; do esforço para o interesse; da disciplina para a espontaneidade; do diretivismo para o não diretivismo; da quantidade para a qualidade;

(...) de uma pedagogia de inspiração filosófica centrada na ciência da lógica para uma pedagogia de inspiração experimental baseada principalmente nas contribuições da bio- 
logia e da psicologia. Esta foi a origem do que hoje tanto se difunde como o aprender, mas aprender a aprender. (Saviani, 1985, p. 13)

Em contraposição, o autor reafirma que a escola é uma instituição cujo papel consiste na socialização do saber sistematizado e, portanto, tem a ver com o problema da ciência e esta é o ponto de partida para a estrutura do currículo. Mas o acesso ao saber científico pode não se constituir em interesse para os estudantes. Abandonar-se-ia, então, a precípua finalidade da escola para se promover outras atividades que despertem maior interesse dos estudantes? A negativa a esta pergunta vem acompanhada do pressuposto de que é papel da escola também educar os interesses dos estudantes.

Um exemplo trazido por Moretti (2007, p. 85), a partir da obra de Leontiev, é elucidativo:

O autor sugere-nos que imaginemos um estudante, ao se preparar para um exame, lendo um livro de História. O que aconteceria se esse estudante ficasse sabendo que essa leitura não é necessária para a realização da prova? Caso ele interrompesse a leitura ficaria claro que o motivo que o levou a ler o livro não era o conteúdo por si mesmo, mas apenas a necessidade de ser aprovado no exame. Aquilo para o qual sua leitura se dirigia não coincidia com aquilo que o induzia a ler. Nesse caso, Leontiev (2001, p. 68) afirma que a leitura não se constituiu, para o estudante, uma atividade, uma vez que sua atividade principal era a preparação para o exame. Por outro lado, caso ele continuasse a leitura, motivado pelo objeto da atividade, teríamos o motivo coincidindo com o objeto e, desta forma, poderíamos afirmar que o estudante se encontrava psicologicamente em atividade.

Com esse exemplo queremos dizer que, possivelmente, o estudante não teria, de imediato, o interesse pela História e leria o livro pela obrigação de fazer o exame. Contudo, o trabalho escolar comprometido com o conhecimento sistematizado não só educaria o interesse do estudante pela História e, assim, pela leitura interessada do livro, como também o levaria ao movimento de questionar, pesquisar, relacionar, enfim, a um processo de aprendizagem que é significativo não porque o conteúdo se vincula formal e/ou artificialmente com situações cotidianas, mas porque possibilitou "produzir, direta e intencionalmente, em cada indivíduo singular, a humanidade que é produzida histórica e coletivamente pelo conjunto dos homens" (Saviani, 2005, p. 13).

É bem verdade que não é somente a intenção de ensinar e de aprender que potencializa a aprendizagem, mas também a efetiva correspondência entre a teoria e sua capacidade explicativa do real, critério de verdade que deveria orientar a seleção de conteúdos. As metodologias proporcionam as mediações necessárias a esse processo, mas não o determinam diretamente. A apologia ao metodologismo e ao cognitivismo, tal como se manifesta por meio de ideias como "metodologias ativas", 
"desenvolvimento de competências" e "aprender a aprender", coloca um cenário que parece instaurar novas possibilidades de formação, mas que, na verdade, secundariza a mais importante dimensão da escola: o acesso ao conhecimento produzido social e historicamente. Este saber, ironicamente, não é negado às elites, mas com frequência parece estar ameaçado para a classe trabalhadora.

É sobre o interesse dos estudantes como meio para mantê-los na escola que também se tem difundido a finalidade profissionalizante do ensino médio, situação que nada tem a ver com a proposta do ensino médio integrado. Essa é, por exemplo, a tônica das estratégias relacionadas à meta 3 , referente ao ensino médio da proposta do Plano Nacional de Educação (PNE), em tramitação no Congresso Nacional.

As estratégias apresentadas para esta meta tomam a educação profissional, seja na forma integrada, seja nas formas concomitante ou sequencial, como um meio de retenção do estudante no ensino médio. A institucionalização do programa nacional de diversificação curricular é também definida como uma estratégia. Tal como foi elaborado, o sentido de formação científica e cultural do currículo é subsumido à intenção de torná-lo interessante aos sujeitos. Reduzir ciência, trabalho, cultura e esporte a dimensões temáticas é considerá-los como contextos de vivências e não como dimensões da formação humana, social e historicamente construídas e determinadas.

Tal redução se confronta radicalmente com o princípio da integração entre trabalho, ciência e cultura como fundamentos epistemológicos e pedagógicos do currículo, que visa à formação omnilateral e politécnica da classe trabalhadora. Ademais, definir a política curricular como a institucionalização de "programa nacional de diversificação curricular" é abster-se de construir uma política curricular no ensino médio.

A vinculação com a atividade profissional parece adquirir grande importância nessa proposta, enviando-se a mensagem de que o ensino médio que interessa aos estudantes é aquele que prepara para o exercício profissional. Se isto parece ser convergente com a concepção de ensino médio integrado que defendemos, tem-se um equívoco, diante do que já expusemos.

Uma das justificativas da proposta sobre pertinência da profissionalização no ensino médio está em proporcionar uma alternativa de formação e de profissão àqueles que não deverão ingressar no ensino superior, expressando a histórica dualidade educacional. A outra justificativa refere-se a tornar o ensino médio mais atrativo aos jovens pela vinculação do ensino ao mercado de trabalho e, assim, ao futuro profissional, corroborando o argumento anterior. Essa atratividade, no ensino médio integrado à educação profissional, adviria da oportunidade de obter logo uma profissionalização. Já no ensino médio não integrado, a atratividade deveria ser 
obtida mediante a inovação curricular, no sentido de incorporar questões vinculadas à vida produtiva.

Como pode ser visto, nossa análise não elide a importância da profissionalização para os jovens, nem a necessidade de se avançar o pensamento sobre o currículo do ensino médio, ultrapassando a marca conteudista e/ou tecnicista que o caracteriza. Mas essas políticas não podem enviesar para o economicismo e o pragmatismo. Estes são vieses radicalmente opostos aos princípios filosóficos e ético-políticos que sustentam a concepção de ensino médio integrado como travessia para a politecnia, defendidos ao longo de todo este texto.

\section{Considerações finais}

Ainda que conceitualmente a política curricular do ensino médio caminhe no sentido da formação integrada, permanecem contradições na existência de diferentes programas que podem ou não estar convergindo numa mesma direção. Ao mesmo tempo, a efetividade do investimento financeiro a que se dispõe o governo federal depende tanto da eficácia administrativa dos sistemas envolvidos, quanto da capacidade deste governo obter hegemonia de suas propostas. E estas, por sua vez, ainda que apresentem, no conteúdo dos documentos oficiais, um compromisso com a classe trabalhadora, deixam transparecer alianças com os interesses do capital. Captar essas contradições nos subsidia para disputar essa mesma política. Os limites abordados são, ao mesmo tempo, de natureza estrutural e conceitual. A disputa conceitual é, na verdade, expressão da disputa por hegemonia travada entre as classes, mais diretamente, por seus intelectuais orgânicos. A classe empresarial tem a hegemonia tanto na sociedade civil quanto na sociedade política. Não obstante, seguindo a visão de Poulantzas (1985) de que o Estado é a condensação da correlação de forças entre as classes, na estrutura estatal temos também pessoas comprometidas com os interesses da classe trabalhadora. Isto explica, a nosso ver, o caráter progressista de alguns documentos, pois estes foram elaborados por intelectuais comprometidos com as lutas sociais e incorporados pelo governo. Não obstante, é na política oficial e no senso comum de seus dirigentes que a concepção de educação comprometida com a classe dominante mais se manifesta.

Do ponto de vista prático, os educadores brasileiros do ensino médio e da educação profissional, assim como a própria sociedade em geral, não incorporaram como sua a concepção de ensino médio integrado na perspectiva da formação omnilateral e politécnica. Ao contrário, predomina uma visão retrógrada vinculada ao ensino médio profissionalizante e compensatória ou, ainda, a defesa de um ensino médio propedêutico e da profissionalização como processo específico e independente. Os trabalhos apresentados no colóquio sobre ensino médio integrado ${ }^{13}$ dão prova 
disso. Identificamos, por exemplo, que a questão conceitual ainda é objeto de muita interrogação e de controvérsia entre professores e gestores, seja pelo insuficiente estudo e conhecimento de seu significado, seja pela opção por propostas geradas no contexto do Decreto n. 2.208/97 e de acordo com as DCN elaboradas pelo CNE para sua implementação.

Finalmente, os segmentos da sociedade que veem positivamente o ensino médio integrado à educação profissional tendem a coincidir com aqueles que dependem da oferta pública da educação básica. Diante da baixa qualidade dessa oferta, a educação profissional não deixa de ser uma alternativa de funcionalidade do ensino, no sentido de proporcionar uma suposta facilidade de ingresso no mercado de trabalho. A oferta concomitante e subsequente da educação profissional segue a mesma lógica. É por isso, a nosso ver, que a ideia - reproduzida como estratégia na proposta de PNE e consubstanciada no Programa Nacional de Acesso ao Ensino Técnico e ao Emprego (PRONATEC) - de se incentivar a oferta gratuita de matrículas na educação profissional pelos setores privados pode ser tão atrativa à sociedade, pois valeria, novamente, como compensação à baixa qualidade do ensino médio público.

O exposto nos parece esclarecer que as dificuldades de implantação do ensino médio integrado se manifestam, inicialmente, como sendo de ordem conceitual, mas são, também, expressão dos limites estruturais dados pela dualidade de classes.

\section{Notas}

1. Referimo-nos aos Pareceres da Câmara de Educação Básica do Conselho Nacional de Educação n. 15/1998 e 16/1999, o primeiro relativo ao ensino médio e o segundo à educação profissional, com as respectivas Resoluções n. 03/1998 e 04/1999. Doravante utilizaremos as siglas DCNEM e DCNEP para designá-las.

2. O Parecer сев/CNE n. 05/2011 apresenta o seguinte esclarecimento: “sobre a adoção do termo "componente curricular", pareceres deste Conselho indicaram que a LDB utiliza diversidade de termos correlatos, empregando concorrentemente e sem rigor conceitual os termos disciplina, componente curricular, estudo, conhecimento, ensino, matéria, conteúdo curricular. O Parecer CNE/CeB n. 05/97, que tratou de Proposta de Regulamentação da Lei n. 9.394/96, indiretamente, já havia unificado aqueles termos, adotando "componente curricular".

3. Discussão detalhada sobre o tema pode ser encontrada em Ramos (2001 e 2010). Na primeira obra, destacamos a relação da pedagogia das competências com o construtivismo piagetiano; já na segunda, a relação com o pragmatismo e com a perspectiva condutivista que essa pedagogia tende a tomar.

4. Referimo-nos aqui a Bernstein (1996) e Santomé (1998). Ver Ramos (2005).

5. Da sua forma transitiva - integrar algo a outra coisa, neste caso, o ensino médio à educação profissional -, essa ampliação conceitual levou à utilização do verbo na forma intransitiva. Ou seja, não se trata somente de integrar um a outro na forma, mas sim de se constituir o ensino médio como um processo formativo que integre as dimensões estruturantes da vida, trabalho, ciência e cultura. Ver Ciavatta e Ramos (2011).

6. Decreto n. 5.840, de 13 de julho de 2006. 
7. Tema abordado por Ciavatta e Ramos (2009).

8. Parecer CNE/CP n. 11/2009.

9. Portaria n. 971, de 9/10/2009.

10. Respectivamente, Parecer CNE/CEB n. 7/2010 e Resolução CNE/CEB n. 4/2010; e Parecer CNE/CEB n. 05/2011.

11. O Parecer CNE/CEB n. 05/2011 esclarece que componentes curriculares são os conteúdos sistematizados que fazem parte do currículo, os quais, por sua vez, se articulam com as áreas de conhecimento, a saber: Linguagens, Matemática, Ciências da Natureza e Ciências Humanas.

12. Parecer CNE/CEB n. 7/2010 e Resolução CNE/CEB n. 4/2010.

13. Realização conjunta do GT Trabalho e Educação, da ANPEd; dos Projetos Integrados coordenados por Frigotto, Ciavatta e Ramos; e pela Direção da EPSJv/FIocruz, no período de 3 e 4 de setembro de 2010, na sede dessa última instituição, no Rio de Janeiro.

\section{Referências}

BRASIL. Lei n. 9.394, de 20 de dezembro de 1996. Diretrizes e Bases da Educação Nacional. Educação profissional: legislação básica. Brasília, DF: PROEP, 1998.

BRASIL. Decreto n. 5.154 de 23 de julho de 2004. Regulamenta o $\S 2^{\circ}$ do art. 36 e os art. 39 a 41 da Lei n. 9.394, de 20 de dezembro de 1996. Disponível em: <http://www.portal. mec.gov.Br/setec/arquivos/pedf_legislação/técnico/legisla_técnico_parecer 1699.pdf. Consulta em 26-2-2009>.

BRASIL. Decreto n. 2.208, de 17 de abril de 1997. Educação profissional: legislação básica. Brasília, DF: PROEP, 1998.

BRASIL. Lei n. 11.741, de 16 de julho de 2008. Altera dispositivos da Lei n. 9.394, de 20 de dezembro de 1996. Disponível em: <http://www.legislação.planalto.gov.br>. Acesso em: 26 fev. 2009.

BRASIL. CNE/CEB. Parecer n. 16, de 5 de outubro de 1999. Diretrizes Curriculares Nacionais de Nível Técnico. Brasília, DF, 1999. Disponível em: <http://www.portal. mec.gov.Br/setec/arquivos/pedf_legislação/técnico/legisla_técnico_parecer 1699.pdf>. Acesso em: 26 fev. 2009.

BRASIL. CNE/CEB. Parecer n. 15, de 1 de junho de 1998. Diretrizes Curriculares Nacionais de Nível Técnico. Brasília, DF, 1998. Disponível em: <http://portal.mec.gov. br/cne/arquivos/pdf/1998/pceb015_98.pdf>. Acesso em: 26 jun 2009>.

BRASIL. CNE/CP. Parecer n. 11, de 30 de outubro de 2009. Proposta de experiência curricular inovadora do Ensino Médio. Brasília, DF, 2009. Disponível em: $<$ http://www.dominiopublico.gov.br/download/texto/me004804.pdf>. Acesso em: 3 jun. 2011. 
BRASIL. CNE/CEB. Parecer n. 5, de 5 de maio de 2011 (Aguardando homologação). Diretrizes Curriculares Nacionais do Ensino Médio. Brasília, DF, 2011. Disponível em: <http://www.portal.mec.gov.br/cne>. Acesso em: 20 jul. 2011.

BRASIL. SEB. Ensino Médio Inovador. Brasília, DF: MEc, 2009. Disponível em: <http:// www.portal.mec.gov.br/seb>. Acesso em: 20 jul. 2011.

BRASIL. SEB. Ensino Médio Inovador. Brasília DF: MEC, 2011. (mimeo.).

BERNSTEIN, B. A estruturação do discurso pedagógico - classe, código e controle. Petrópolis: Vozes, 1996.

FRIGOTTO, G. A interdisciplinaridade como necessidade e como problema nas ciências sociais. In: JANTSCH, A.P.; BIANCHETTI, L. (Org.). A interdisciplinaridade: para além da filosofia do sujeito. Petrópolis: Vozes, 1995. p. 25-49.

GRAMSCI, A. Os intelectuais e a organização da cultura. Rio de Janeiro: Civilização Brasileira, 1991.

KOSIK, K. Dialética do concreto. Petrópolis: Vozes, 1978.

LUKÁCS, G. Per una ontologia dell'essere sociale. Trad. de Ivo Tonet. Roma: Riuniti, 1981. Capítulo 1.

MARX, K. Para a crítica da economia política. São Paulo, Abril Cultural, 1978. p. 103132.

CIAVATTA, M.; RAMOS, M.N. Ensino médio integrado. Verbete. In: Dicionário de Educação do Campo. Rio de Janeiro: EPsJv; FIOCRUz, 2011. (No prelo).

CIAVATTA, M.; RAMOS, M.N. Ensino médio e educação profissional: a visão da imprensa e a dualidade na concepção do ensino médio integrado. In: Anuário da Educação na Imprensa. São Paulo: Cortez, 2011. (No prelo).

MORETTI, V. Professores de matemática em atividade de ensino: uma perspectiva histórico-cultural para a formação docente. 2007. Tese (doutorado em Educação) - Universidade de São Paulo. São Paulo.

PERRENOUD, P. Construir as competências desde a escola. Porto Alegre: Artes Médicas, 1999.

POULANTZAS, N. O Estado, o poder, o socialismo. 3. ed. Rio de Janeiro: Graal, 1985.

RAMOS, M.N. A pedagogia das competências: autonomia ou adaptação. São Paulo: Cortez, 2001.

RAMOS, M.N. O projeto unitário do ensino médio sob os princípios do trabalho, da 
O currículo para o ensino médio em suas diferentes modalidades...

ciência e da cultura. In: Frigotto, G.; Ciavatta, M. Ensino médio: ciência, cultura e trabalho. Brasília, DF: MEC, 2004. p. 37-52.

RAMOS, M.N. Possibilidades e desafios do currículo integrado. In: Frigotto, G.; Ciavatta, M.; Ramos, M.N. Ensino médio integrado: concepção e contradições. 1. ed. São Paulo: Cortez, 2005. p. 106-127.

RAMOS, M.N. Trabalho, educação e correntes pedagógicas no Brasil: um estudo a partir da formação dos trabalhadores técnicos da saúde. Rio de Janeiro: EDUfRJ; EPSJv/FIoCRUZ, 2010.

SANTOMÉ, J. Globalização e interdisciplinaridade: o currículo integrado. Porto Alegre: Artes Médicas, 1998.

SAVIANI, D. Escola e democracia. São Paulo: Cortez, 1985.

SAVIANI, D. Escola e democracia. Ed. comemorativa. São Paulo: Cortez, 2008.

SAVIANI, D. Pedagogia histórico-crítica. Campinas: Autores Associados, 2005.

Recebido em 28 de junho de 2011.

Aprovado em 10 de agosto de 2011. 